\title{
Evaluation of 15 Years Practice of Coelioscopic Treatment of Ectopic Pregnancy in the Surgery Department " $A$ " at the University Hospital Point G
}

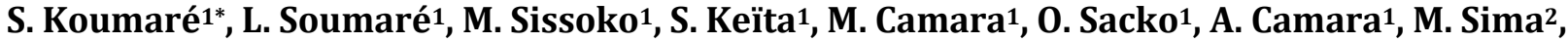 \\ M. Traoré ${ }^{2}$, H. Dicko³ ${ }^{3}$ B. Bengali4, D. Traoré ${ }^{4}$, S. Togo ${ }^{5}$, D. Koné ${ }^{1}$, S. Diallo ${ }^{4}$, M. Sangaré6, A. Koïta ${ }^{1}$, \\ Z. Z. Sanogo' ${ }^{1}$ D. Sangaré1
}

${ }^{1}$ Department of Surgery “A”, University Hospital of Point G, Bamako, Mali

${ }^{2}$ Department of Gynecology-Obstetrics, University Hospital of Point G, Bamako, Mali

${ }^{3}$ Department of Intensive Care, University Hospital of Point G, Bamako, Mali

${ }^{4}$ Department of Surgery “B”, University Hospital of Point G, Bamako, Mali

${ }^{5}$ Department of Thoracic and Cardiovascular Surgery, Hospital of Mali, Bamako, Mali

${ }^{6}$ Faculty of Medicine and Odontostomatology (FMOS), University of Sciences, Techniques and Technologies of Bamako (USTTB), Bamako, Mali

Email: *Sekou_koumare@yahoo.fr

How to cite this paper: Koumaré, S., Soumaré, L., Sissoko, M., Keïta, S., Camara, M., Sacko, O., Camara, A., Sima, M., Traoré, M., Dicko, H., Bengali, B., Traoré, D., Togo, S., Koné, D., Diallo, S., Sangaré, M., Koïta, A., Sanogo, Z.Z. and Sangaré, D. (2018) Evaluation of 15 Years Practice of Coelioscopic Treatment of Ectopic Pregnancy in the Surgery Department "A" at the University Hospital Point G. Surgical Science, 9, 454-460.

https://doi.org/10.4236/ss.2018.911051

Received: October 19, 2018

Accepted: November 27, 2018

Published: November 30, 2018

Copyright (๑) 2018 by authors and Scientific Research Publishing Inc. This work is licensed under the Creative Commons Attribution-NonCommercial International License (CC BY-NC 4.0). http://creativecommons.org/licenses/by-nc/4.0/

\begin{abstract}
Aim: To evaluate 15 years practice of coelioscopic Treatment of ectopicpregnancy in the Surgery Department "A" at the University Hospital Point G. Material and Methods: We conducted a descriptive retrospective study at the Surgery Department "A" at the University Hospital Point G from January 2001 to August 2015. Inclusion criteria were all pregnant women with ectopic pregnancy treated with coelioscopy. Sociodemographic, clinical, paracclinical and therapeutic aspects were recorded. Results: In 15 years, 42 cases of ectopic pregnancy out of 3840 gynecologic coelioscopies (1.04\%) were collected. The average age was 28.5 years old with the extremes of 16 and 41 years old. Metrorragia was associated to pain in $83.3 \%$ (35/42); amenorrhea was found in $66.7 \%(28 / 41)$. Physical exam revealed pain with abdominal defense in $59.5 \%(25 / 42)$, adnexal mass in $31 \%(13 / 42)$, and pelvic contracture in $9.5 \%$ (4/42). In pre-operative, ectopic pregnancy was diagnosed complicated in $71.4 \%(30 / 42)$ and uncomplicated in $28.6 \%$ (12/42). Patients underwent salpingectomy in $85.7 \%$ (36/42), delivery from the fallopian tube in $9.8 \%(4 / 42)$, and hemostatic salpingectomy in $4.4 \%(2 / 42)$. The average duration of hospital stay was 1.88 day with the extremes of 1 and 7 days. The postoperative evolution was favorable in $97.6 \%$ (41/42), infection at the site of surgery was
\end{abstract}


reported in $2.4 \%(1 / 42)$. Not a single death was registered. Conclusion: Treatment of ectopic pregnancy is of routine at the surgery department " $A$ " in Point G. Fertility is preserved in the future.

\section{Keywords}

Ectopic Pregnancy, Coelioscopic Surgery “A”, CHU Point G

\section{Introduction}

Ectopic pregnancy is defined as a pregnancy that develops outside the uterine cavity [1]. Since two decades, the progressive increase in the frequency of extra-uterine pregnancy in developed countries has been accompanied by a revolution in its diagnostic and treatment. Ectopic pregnancy is more and more treated by conservative coelioscopic and medical methods [2].

Ectopic pregnancy is a surgical emergency, which can compromise the vital prognostic and fertility of the patient. The diagnostic is clinical and paraclinical without any delay. In 1992, ectopic pregnancy was the first cause of mortality in first trimester pregnancy in the U.S. [3]. Its prevalence was $1 \%-2 \%$ of all pregnancies with nine out of ten occurring in the fallopian tube. In 1996, 25 cases of ectopic pregnancy were collected at the childbirth place in Orangers, France. The coelioscopic treatment necessitated $80 \%$ of salpingectomy.

In Mali, ectopic pregnancy has extensively been studied [4] reaching the conclusion that it is the first cause of maternal mortality in the first trimester of pregnancy. However, the lack of data on the coelioscopic approach motivated our study at the surgery department "A" at the University hospital Point G.

\section{Patients and Methods}

We conducted a descriptive and retrospective study at the Surgery Department "A" at the University Hospital Point G from January 2001 to August 2015. Inclusion criteria were all pregnant women with ectopic pregnancy treated with coelioscopy. Exclusion criteria were those operated by other approaches such as laparotomy and those with an incomplete medical chart. The preparatory protocol included an emergent pre-operatory analysis, abdominal ultrasound and $\beta$-HCG test. Sociodemographic, clinical, paraclinical and therapeutic aspects as well as the post-operatory evolution were recorded parameters in our study.

\section{Results}

In 15 years, we realized 8610 surgical interventions including 42 cases of ectopic pregnancy among 3840 cases of gynecologic coelioscopy (1.04\%). Patients were 28.5 years old on average with the extremes of 16 and 41 years old. Patients were housekeepers in 61.9\% (26/42), school girls in 33.3\% (14/42), and highly educated women in $4.8 \%(2 / 42)$. Patients were referred by primary physicians in 
$52.4 \%(22 / 42)$ and OBG doctors in $4.8 \%(2 / 42)$; they came by themselves in $2.9 \%$ $(18 / 42)$. The main motive of complaint was painful metrorragia in $83.3 \%$ (35/42). Anamnesis revealed amenorrhea in 66.7\% (28/42).

Ectopic pregnancy lasted less than three days in $38.1 \%(16 / 42), 3-7$ days in $59.5 \%(25 / 42)$ and more than seven days in $2.4 \%$ (1/42). Patients had five or more births in $52.4 \%(22 / 42)$, a single birth in $30.95 \%(13 / 42)$ and anywhere in between in $16.67 \%$ (7/42). Patients had medico-surgical history of genital infection in $61.9 \%(26 / 42)$, abortion in $9.5 \%(4 / 42)$, laparatomy in $4.8 \%(2 / 42)$, breast nodule ablation in $2.4 \%(1 / 42)$. Sociodemographic and clinical characteristics of participants were illustrated in Table 1 and Table 2.

Hemoglobin was less than $12 \mathrm{~g} / \mathrm{L}$ in $92.9 \%(39 / 42)$ and more than $12 \mathrm{~g} / \mathrm{L}$ in $7.1 \%$ (3/42). Ultrasound showed a ruptured ectopic pregnancy in $40.5 \%(17 / 42)$ and uncomplicated in $35.7 \%$ (15/42). Per-operatory diagnostic was ruptured ectopic pregnancy in $71.4 \%(30 / 42)$. Ectopic pregnancy was in the ampulla in $66.7 \%(28 / 42)$, in the isthmus in $23.8 \%$ (10/42), and in the infundibulum in $9.5 \%$ (4/42). Surgical procedures were salpingectomy in $85.7 \%(36 / 42)$, delivery from the fallopian tube in $9.8 \%(4 / 42)$, and hemostatic salpingectomy in $4.4 \%(2 / 42)$. The average duration of hospital stay was 1.88 day with the extremes of 1 and 7 days. The postoperative evolution was favorable in $97.6 \%$ (41/42), infection at the site of surgery was reported in $2.4 \%(1 / 42)$ without a single death.

Figures 1-3 were the illustrations of per-operatory coelioscopic pictures of ectopic pregnancy at the surgery " $A$ " department of the University hospital Point G in Bamako, Mali.

\section{Discussion}

Gynecologic surgery occupied $44.6 \%$ of our coelioscopic activities in the surgery department " $\mathrm{A}$ " including 1.04\% ectopic pregnancy. This proportion seems low

Table 1. Job of participants.

\begin{tabular}{ccc}
\hline Job & Frequency & Percentage \\
\hline housekeepers & 26 & $61.9 \%$ \\
school girls & 14 & $33.3 \%$ \\
highly educated women & 2 & $4.8 \%$ \\
Total & 42 & $100 \%$ \\
\hline
\end{tabular}

Table 2. Physical exam results of participants.

\begin{tabular}{ccc}
\hline Physical exam & Frequency & Percentage (\%) \\
\hline Pelvic defense & 25 & $59.5 \%$ \\
Adnexal mass & 13 & $31 \%$ \\
Pelvic contracture & 4 & $9.5 \%$ \\
Conjonctival pallor & 27 & $31 \%$ \\
WHO performance index grade 0 & 26 & $61.9 \%$ \\
\hline
\end{tabular}




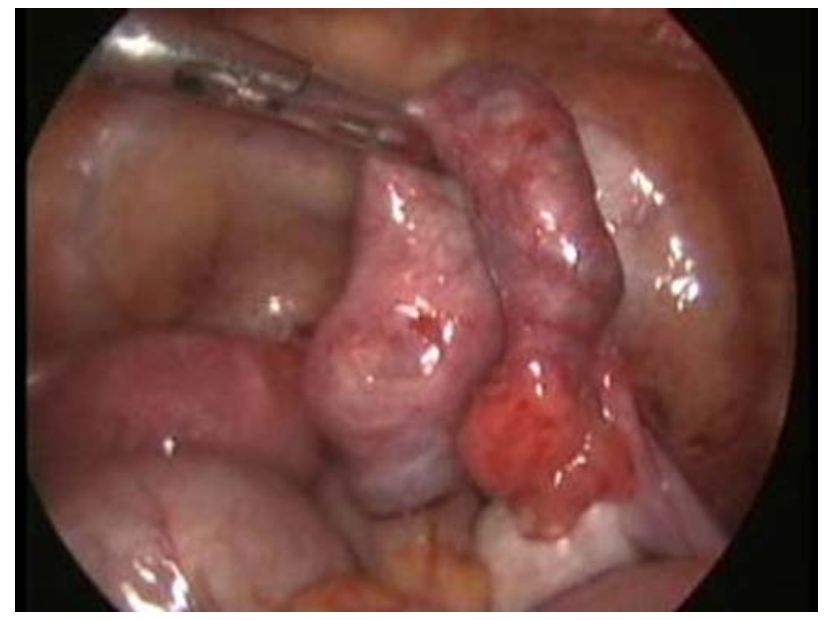

Figure 1. Non ruptured right ampullar ectopic pregnancy.

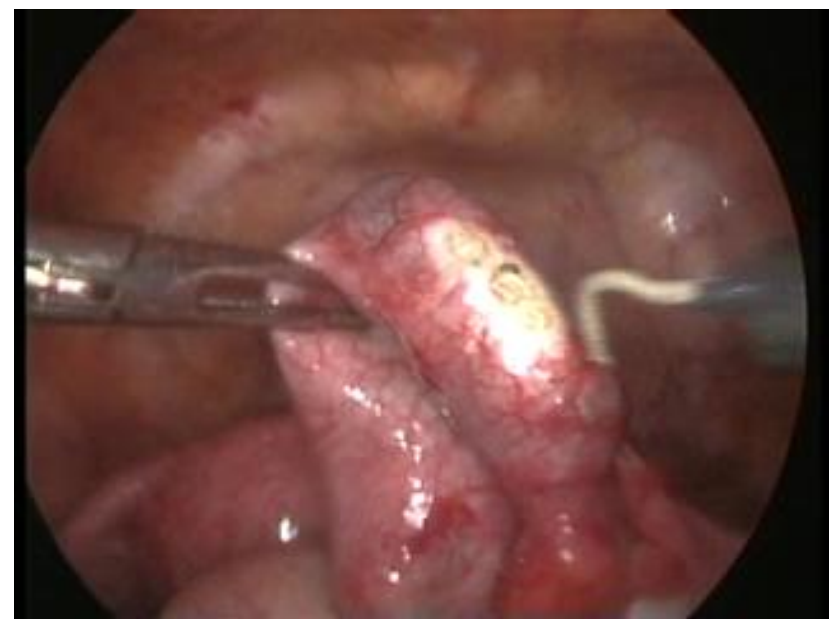

Figure 2. Electrocoagulation on the anti-mesial border of the fallopian tube.

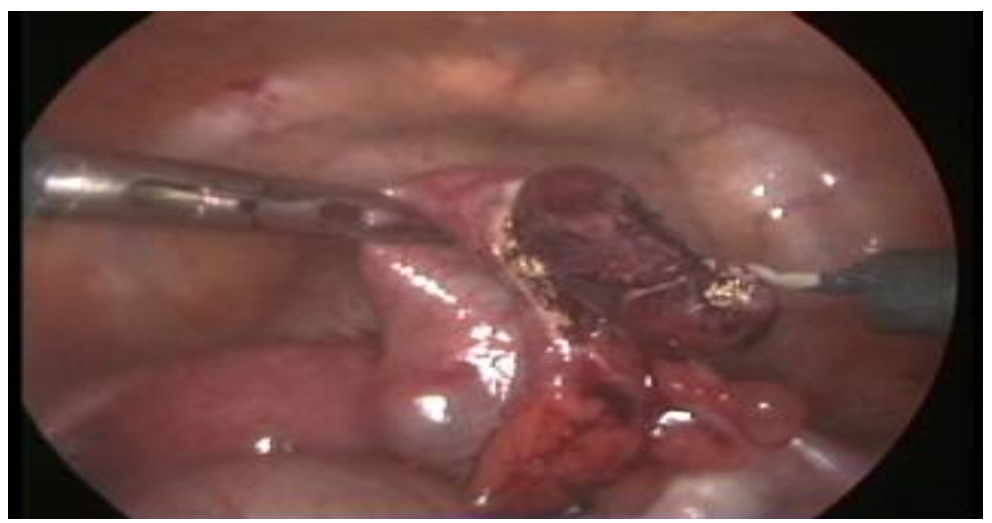

Figure 3. Salpingotomy and extraction of trophoblast.

as compared to many other studies, but we are a general surgery department whose patients are mainly referred by gynecologists and primary physicians (57.1\%). Ectopic pregnancy was as frequent as $6 \%-12 \% \mathrm{p}<0.05$ in Cameroun and Gabon [5] [6] and its frequency was $2.4 \%$ in the department district in south 
N'diamena (Tchad) in 2015 [7]. In 2003, its frequency had doubled over the last 15 years (2\% of all pregnancies) or 14,000 per year in France according to the CNGOF (French National college of Obstetricians and Gynecologists) [8]. This recrudescence may be linked to risk factors such as chronic salpingitis, tubular surgery, tobacco smoking, clandestine abortion and anatomical anomalies.

The mean age in our cohort was 28.5 years old comparable with 32 years old in Senegal and 31 years old from the regional registry in Auberge, France [8] [9]. No relationship was found between age and the occurrence of ectopic pregnancy $\mathrm{p}>0.05$. Functional symptomatology was dominated by pelvic pain, adnexal mass and amenorrhea similar to what was found in the literature [4] [5] [8] [9]. Complementary exams for diagnostic were essentially based on abdominal ultrasound, which occupies a place of choice in the diagnostic of ectopic pregnancy. Its informs on the site, morphological aspect (either ruptured or non-ruptured), abundance of hemorrhage [1] [4] [7]. The type of surgery to be performed is determined after clinical and paraclinical evaluation including emergent anesthetic consultation. This evaluation was aimed to take the necessary pre-operatory steps to minimize the per-operatory accidents.

In per-operatory setting, the ectopic pregnancy was ruptured in $71.4 \%$ in our cohort similar to $80 \%$ from a study in Gabon [6] p $>0.05$. This high frequency might have resulted from delayed diagnostic. Ectopic pregnancy was located in the right fallopian tube in $85.7 \%$ (Figure 1) and its distal and medial one thirds were affected in $66.7 \%$ and $9.5 \%$, respectively similar to the data from the literature [10]. These parts of the fallopian tube host the ampulla, which is the most dilated and spacious part of the tubular formation.

The surgical procedure was dominated by salpingectomy in $85.7 \%(36 / 42)$ followed by delivery from the fallopian tube in $9.8 \%(4 / 42)$. Salpingectomy consists to electro coagulate the anti-mesial border of the fallopian tube (Figure 2), to open and evacuate the trophoblastic content (Figure 3), then to clean the peritoneal cavity. This technique allows not only to conserve the fallopian tube, but also to preserve the chance for future pregnancies. This procedure has been adopted by some authors [11]. Hemostatic salpingectomy was practiced in $4.4 \%$ $(2 / 42)$. Other authors did the same technique when blood collected in the abdominal cavity was abundant [5] [6] [9]. Certain clinical vignettes impose salpingectomy especially in case of ruptured and damaged fallopian tube, ectopic pregnancy on either pathologic fallopian tube or one that has previously been affected by ectopic pregnancy as well as cataclysmic hemorrhages.

The average hospital stay was 1.33 days with the extremes of one and five days. This was in line with the classical benefits of coelioscopic surgery namely short hospitalization, minor surgical sequellae on the parietal part of the abdomen, quick return to physical and professional activities. Our findings were similar to the data in the literature [12] [13] [14]. The rate of hospitalization exceeding 72 hours was $11.9 \%$ due to the necessity to monitor closely patients who benefited from blood transfusion. No accident happened during the interventions. Open coelioscopy has allowed us to avoid accidents resulting from the in- 
troduction of the first needle [15]. Post-operatory morbidity was $2.4 \%$, another advantage of coelioscopy [16] [17].

\section{Conclusion}

The coelioscopic treatment of ectopic pregnancy is of routine in the surgery department " $A$ " at the University hospital Point G. Morbidity and mortality are reduced with the conservation of the fallopian tube and preservation of future fertility.

\section{Conflicts of Interest}

The authors declare no conflicts of interest regarding the publication of this paper.

\section{References}

[1] Bouyer, J., Fernandez, H., Coste, J., Pouly, J.L. and Jobs-Spira, N. (2003) Fertilité après grossesse extra-utérine, résultats sur 10 ans du registre d'Aubergne. Journal de Gynécologie Obstétrique et Biologie de la Reproduction, 32, 431-438.

[2] Manhès, H. (2003) $1^{\text {ère }}$ GEU opérée par voie coelioscopique. Le Journal de Coelio-Chirurgie, 48, 7-9.

[3] Salvat, J. and Melis Thonon, A. (2006) Cœlioscopie et grossesse en gynécologie (en dehors de la grossesse extra-utérine). Revue de la littérature. Le Journal de Coelio-Chirurgie, 57, 13-43.

[4] Sanogo, Z.Z., Koïta, A.K., Keita, S., et al. (2014) Apport de la néosalpingostomie coelioscopique dans le traitement de l'infertilité tubaire. Le Journal de Coelio-Chirurgie, 91, 51-54.

[5] Picaud, A. (1993) Mortalité de la grossesse extra utérine à Libreville; département de gynécologie obstétricale du CHU de Libreville (Gabon). Médecine d Afrique noire, 40, 1-5.

[6] Kenfack, B. et al. (2012) La grossesse Extra-Utérine dans une région semi-rurale en Afrique: aspects épidémiologiques, cliniques et thérapeutiques à propos d'une série de 74 cas traités à l'hôpital de District de Sangmelima au Sud Cameroun. Pan African Medical Journal, 13, 71.

[7] Madoue, G.B., Saleh, A., Wilfried, I.S.R., Tchari, A. and Kolomso, D. (2015) Grossesse extra-uterine: Aspects épidémiologiques et Pronostic maternel à l'Hôpital de district de N'djamena sud (Tchad). Kisangani Medical, 6, 111-116.

[8] Élaborées par le Collège National des Gynécologues et Obstétriciens Français (2003) Prise en charge de la grossesse extra-utérine. Journal de Gynécologie Obstétrique et Biologie de la Reproduction, 32, 3S6-3S112.

[9] Niang, M.M., Aidibe, I. and Cisse, C.T. (2013) La grossesse hétérotopique spontanée à l'institut d'hygiène sociale de Dakar. Médecine d Afrique Noire, 60, 263-268.

[10] Dupuis, O., Camagna, O., Benifla, J.L., Batallan, A., Dhainaut-Renolleau, C. and Madelenat, P. (2001) Grossesse Extra-Utérine. EMC-Gynécologie-Obstétrique, 5-032-A-30, 18 p.

[11] Salvat, J. and Thonon, A.M. (2006) Cœlioscopie et grossèsse en gynécologie (en dehors de la grossesse extra-utérine). Le Journal de Coeliochirurgie, 57, 35-39.

[12] Dubuisson, J.B., Aubriot, F.X., Foulot, H., Bruel, D., Bouquet de Jolinière, J. and 
Mandelbrot, L. (1990) Reproductive Outcome after Laparoscopic Salpingectomy for Tubal Pregnancies. Fertility and Sterility, 53, 1004-1007. https://doi.org/10.1016/S0015-0282(16)53575-4

[13] Krebs, H.B. (1986) Intestinal Injury in Gynecologic Surgery: A Ten-Year Experience. American Journal of Obstetrics and Gynecology, 155, 509-514. https://doi.org/10.1016/0002-9378(86)90268-1

[14] Engongah-Beka, T., Meye, J.F., Ozouaki, F. and Sima-Ole, B. (1997) Association grossesse intra-utérine et extra-utérine rompueà propos de 2 cas d'évolution différente et revue de la littérature. Médecine d’ Afrique Noire, 44, 472-475.

[15] Jabahgi, S. and Levy, M. (2001) Colio-appendicectomie extra-abdominale par voie trans-ombilicale. Le Journal de Coeliochirurgie, 40, 62-65.

[16] Soutoul, J.H. and Pierre, F. (1988) Les risques médico-légaux de la cœlioscopie. Analyse de 32 dossiers de complications. Journal de Gynécologie Obstétrique et Biologie de la Reproduction, 17, 439-451.

[17] Heloury, Y., Leclair, M.D., Camby, C. and Podevin, G. (2001) Place de la cœlioscopie en gynécologie pédiatrique. Le Journal de Coeliochirurgie, 37, 52-55. 